Essence of biophysics

Molecular Biophysics. By M. V. Volkenstein. Pp.621. (Academic: New York and London, 1977.) \$36.50; $£ 25.90$.

PROFESSOR Volkenstein's many friends and admirers will be delighted that his latest book, published in its original Russian version some two years ago, is now accessible to a wider scientific public. Although intended as a more or less introductory text, it displays the same lucid and seemingly effortless scholarship which characterised his earlier and classic treaties Molecular Optics, Vibrations of Molecules and Congurational Statistics of Polymer Chains (which is unaccountably the only other one presently available in English translation).

Volkenstein stands in the great tradition of Russian theoretical physics, and early in his career came under the influence of such men as Landau, Tamm, and particularly Mandelstam, in whose laboratory he made his reputation with contributions of classic stature on the theory of optical activity and on Raman spectroscopy. In the early 1950s he was drawn, along with many of his most brilliant contemporaries, into polymer science, and with Tsvetkov, Frenkel, Frisman and Bresler, created in Leningrad a major centre of research in this area. There Volkenstein attracted a group of exceptional younger workers, including Ptitsyn, Birshtein, Gotlieb and Eisner, and inevitably they turned their attention increasingly to the rapidly burgeoning field of biopolymers. As one of many visiting workers from all over the world, I had the privilege of witnessing the excitement of this new venture and experiencing the intensity of the intellectual ferment which Volkenstein is unfailingly able to generate.

Characteristically Volkenstein has progressed from his initial preoccupation with the structure and conformational transitions of biopolymers into central questions of biological function. In the introduction to this book he gives a definition of a biophysicist, or perhaps a credo: "A biophysicist is a physicist possessing broad biological erudition, who is also able to formulate and solve physical problems. Biological erudition, implies more than the knowledge of the special fields of biology bearing directly on the subject at hand, say molecular biology or physiology. One who is alien to living nature, who is not familiar with zoology and botany, does not understand biology". Erudition indeed is a quality that Volkenstein possesses in abundance.
His emphasis is essentially scholarly, rather than pragmatic, and in this he follows the traditional precepts of the Russian school of physics. His book thus concerns itself more with the creation of a satisfying intellectual framework than with the detailed description of phenomena. It concentrates also on the topics that can usefully be treated with some critical rigour, which makes it less important that the references stop at 1975 .

The book deals with the basis of the physical methods used to study proteins and nucleic acids in both structural and dynamic terms. It is particularly strong on cooperative phenomena, but the broader physical principles of enzymology and biosynthesis are not neglected. Theoretical arguments are developed in relatively leisurely fashion, but the more tedious mathematical manipulating are omitted. The result is a very readable book, which carries the reader along very compellingly. The translation (by an anonymous hand, presumably that of the author himself) is smooth, and, as

\section{Scanning electron microscopy}

Introduction to Biological Scanning Electron Microscopy. By M. A. Hayat. Pp. 323 (University Park Press: Baltimore, Maryland, London and Tokyo, 1978.) £9.25.

IN the first sentence of this book the author acknowledges that it is a most demanding task to write a relatively short volume aimed at both beginning and experienced workers. Hayat is unfortunately hoist by his own petard, for this book would be confusing for the beginner and is infuriating for the experienced microscopist. The volume is split into two parts: the first deals briefly with the instrumentation of the scanning microscope, the second and longer part with specimen preparation.

The first section on instrumentation, though covering most of the main points, does so in such a spartan manner that a beginner would find it difficult to know how to operate the instrument to obtain maximum information from his specimen. The author clearly considers biologists are innumerate, for this whole section is devoid of any equations, which surely must be the most concise way of explaining electron optics.

The section on specimen preparation is no more than a compilation of other people's work and with the exception of the section on fixation there is little to persuade the reader that the author has had first-hand experience with the techniques he describes. Although numerous recipes are given for the various manoeuvres of specimen preparation, the author far I am capable of judging, in excellent style.

To my knowledge, there is no rival textbook in the field. Volkenstein's coverage is more mathematical and rigorous than, for example, van Holde's Physical Biochemistry, and it assumes a grounding in physical science at the degree level. It therefore fills a real need, and cannot help but appeal particularly to physicists and physical chemists entering biological research. The book is well produced and reasonably priced by today's rather alarming Western standards. I anticipate that many graduate students and research fellows will have good reason to be grateful to both the author and his publishers for many years to come.

D. Z. Staynov

D. Z. Staynov is a member of the staff of the Institute of Molecular Biology of the Bulgarian Academy of Sciences in Sofia, and is currently SRC Senior Visiting Research Fellow in the Department of Biophysics, King's College, University of London, $U K$.

is insufficiently incisive in separating fact from conjecture and fails to critically assess the relative merits and faults of the different techniques. The beginner would be left floundering trying to decide on the best course of action, and the experienced microscopist would find little recourse to refer to this section.

The text is sadly unbalanced. Most of the methodology is directed towards mammalian tissue, with only lip service given to invertebrates, plants and microorganisms. Stereo techniques, which are at the heart of quantitative microscopy, are dismissed in half a page, whereas over 20 pages are devoted to cataloguing cell surface labelling methods. Eight pages of pictures are devoted to illustrating the various containers which may be used during critical point drying, but no pictures illustrate the section on the artefacts which can arise during specimen processing. The scanning microscope invariably provides visually satisfying images, and it is sad that the author has limited himself to 20 rather poor scanning micrographs to illustrate over 300 pages of text.

Regrettably, this is a far from satisfactory book, and cannot be considered as a vade-mecum for biological scanning microscopists. Experienced microscopists will quickly realise that it lacks any authority and the beginner will find that it gives neither the rationale behind applying a particular course of action nor a concise statement of how best to carry it out.

Patrick Echlin

Patrick Echlin is Assistant Director of Research at the Botany School, University of Cambridge, UK. 